\title{
SOCIODEMOGRAPHIC AND CLINICAL FACTORS ASSOCIATED WITH LOW QUALITY OF LIFE ONE YEAR AFTER CORONARY BYPASS OPERATIONS: THE ISRAELI CORONARY ARTERY BYPASS STUDY (ISCAB)
}

\author{
Elisheva Simchen, MD, MPH ${ }^{\mathrm{a}, \mathrm{b}}$ \\ Noya Galai, $\mathrm{PhD}^{\mathrm{a}, \mathrm{c}}$ \\ Dalit Braun, MSC \\ Yana Zitser-Gurevich, MD, MPH ${ }^{\mathrm{a}}$ \\ Eti Shabtai, MSC ${ }^{\text {a }}$ \\ Irit Naveh, RN, MSC ${ }^{\mathrm{a}}$ \\ For The ISCAB consortium*
}

Objectives: We sought to examine the effect of sociodemographic characteristics and perioperative clinical factors 1 year after coronary bypass operations on low health-related quality of life. We also sought to assess the usefulness of an additional single question on overall health for identifying patients with low health-related quality of life.

Methods: This report is part of the Israeli coronary artery bypass study of 1994 , in which every patient undergoing isolated coronary bypass grafting in Israel was included. The target population for this report comprised all survivors beyond 1 year who were 45 to 65 years of age. Patients were interviewed before the operations. Self-administered questionnaires regarding health-related quality of life (SF-36) were sent to 1724 patients who were successfully located 1 year postoperatively, and 1270 questionnaires were completed. Low health-related quality of life was defined as the lowest tertile of the distribution of scores for the 2 summary components of the SF-36 and the single question on overall health. Logistic models were constructed for each of the 3 outcomes.

Results: Female sex and low socioeconomic background were associated with low health-related quality of life in the logistic models. Other significant factors were symptoms of angina, sleep disturbances, hypertension, high severity of illness scores, hospital readmission, no rehabilitation, and hospitals with high perioperative mortality. Of the 3 study outcomes, the model for the single question on overall health was the most discriminating (C statistic $=0.76$ vs 0.70 and 0.70 , respectively).

Conclusions: The study identifies patients who would most benefit from posthospitalization community support after bypass operations. Under circumstances of limited resources, these disadvantaged groups should be targeted as a priority. Encouraging participation in existing rehabilitation programs or introducing telephone hotlines could improve health-related quality of life after coronary bypass grafting without large investments. (J Thorac Cardiovasc Surg 2001;121:909-19)

$T_{\text {hes }}^{\text {hes }}$ here is evidence that improvement in survival among patients undergoing coronary artery bypass grafting (CABG) compared with those undergoing other modes

From the Department of Health Services Research, Ministry of Health, ${ }^{a}$ the Department of Social Medicine and School of Public Health, The Hebrew University and Hadassah Medical Center, ${ }^{b}$ Jerusalem, and the Department of Epidemiology, Ben Gurion University, ${ }^{\mathrm{c}}$ Beer Sheva, Israel.

Supported by the Ministry of Health, Israel.

*For members of the Israeli Coronary Artery Bypass Study, see end of article.

Copyright (C) 2001 by The American Association for Thoracic Surgery

0022-5223/2001 $\$ 35.00+0 \quad \mathbf{1 2 / 1 / 1 1 2 8 3 0}$

doi:10.1067/mtc.2001.112830 of treatment is greatest for the most severe types of coronary heart disease. For the milder cases, the main improvement is in quality of life. ${ }^{1,2}$ Thus, quality of life, in addition to survival, is an important outcome of bypass operations. However, very few articles in the literature use multivariate models to identify factors associated with health-related quality of life (HRQOL) after $\mathrm{CABG}^{3,4}$ We used a national study of all patients undergoing CABG during 1994 in Israel to follow up patients and ascertain their quality of life 1 year after the operation. We chose the Short Form-36 (SF-36) health survey questionnaire as the generic tool because it was easy for patients to use, was widely validated (including in a sample of the Israeli population), and 
was formally translated into Hebrew (Shmueli A, Shabtai E, unpublished data). ${ }^{5}$ The SF-36 uses the HRQOL concept rather than quality of life in general. It is a concept that "quantifies the impact of illness on life." ${ }^{\prime 6}$ Another feature of the SF-36 was in using selfperceptions of the patients themselves ${ }^{7,8}$ rather than the opinions of caregivers.

The SF-36 questionnaire is composed of 36 questions forming 8 scales for different aspects of HRQOL: Physical Functioning, Mental Health, Bodily Pain, Role-Physical, Role-Emotional, Vitality, Social Functioning, and General Health. These 8 scales are reduced to 2 summary components, one for mental and one for physical health. This article attempts to identify factors associated with having low scores for either the physical or the mental component of the SF-36 or answering negatively to a single question concerning overall health.

This study was not designed as an evaluation of the efficacy of bypass operations, which would require a comparison of HRQOL before and after the operation, ${ }^{9-14}$ nor does it contrast HRQOL of patients undergoing bypass with that of patients undergoing other procedures, such as percutaneous transluminal coronary angioplasty. ${ }^{15-20}$ Rather, the interest was in identifying those who reported a less-favorable outcome and then exploring the reasons why they did so. We chose preretirement patients as the subject of this article because these patients faced special challenges, such as the expectation that they return to active participation in the labor force. ${ }^{21}$

\section{Material and methods}

This article is part of the Israeli Coronary Artery Bypass Graft study, for which every isolated CABG operation in 1994 was eligible. All 14 institutions performing the operation, including private institutions, enrolled patients between January 1 and December 31, 1994. Of the survivors in 1 year, 2085 were men and women aged 45 to 65 years. Of this target population, $361(17 \%)$ patients could not be tracked 1 year after their operation (eg, foreign residence or wrong address or telephone number given at the time of the initial interview). Of the 1724 patients who received the mailed questionnaires, $900(52.2 \%)$ responded without additional contact, and the remaining 624 received 2 additional telephone calls to promote response. Of this last group, 370 (59\%) complied. This brought the total number of returned questionnaires to 1270 , corresponding to a response rate of $73.6 \%$ among those who could be tracked. A comparison of various characteristics of responders and nonresponders (appendix) was made to examine the possibility of a bias introduced by the incomplete response rate.

Sources of data. Initial hospitalization data included a preoperative interview of sociodemographic and behavioral characteristics, as well as a history of the coronary disease and its extent. A catheterization and operation report, daily follow-up, and a summary of the hospitalization completed the original data files. Hospital readmission and participation in rehabilitation programs within 100 days after the operation were independently ascertained. SF-36 questionnaires were sent to survivors 1 year after the operations.

Patients who entered the study during the last 2 weeks of $1994(\mathrm{n}=200)$ were asked to fill out an SF-36 questionnaire before the operation. Of these, 116 patients aged 45 to 65 years returned postoperative questionnaires 1 year later and thus could be analyzed for the effect of the preoperative scores on the postoperative quality-of-life evaluation.

Study outcomes. The average scores of patients on each of the 8 scales of the SF-36 were used for descriptive comparisons between subgroups of patients. However, for the multivariate modeling of the determinants of quality of life, 3 outcomes were defined: the 2 summary components of the SF-36 (because there is no single summary score for quality of life) and a single question on overall health. The Physical Component Score (PCS) and the Mental Component Score (MCS) of the SF-36 are based on the same 8 original scales but with different weights assigned to them. ${ }^{22-25}$ Each of the summary scores can range from 0 to 100 . The third outcome was a single question evaluating the patient's perception of his or her health: "In general, would you say your health is excellent, very good, good, fair, or poor."

For modeling purposes, we dichotomized the 2 summary components of the SF-36 into "low" and "not low" categories. The same was done with the single question on quality of life. Because there is no recognized standard of high or low HRQOL, we used the low end of the score distribution of each of the 2 summary components as our definition of low HRQOL. The choice of a cutoff point for the definition of low HRQOL was influenced by the finding that $33 \%$ of the patients had a negative evaluation on the category of overall health. To maintain consistency, we defined, in turn, low physical health (PCS) and low mental health (MCS) as the lowest $33 \%$ of their respective distributions. Empirically, these cutoff points corresponded to scores of 39.0 and 41.0 for PCS and MCS, respectively. As reference for interpretation, the average scores for the entire CABG population were 43.3 and 46.2 for PCS and MCS, respectively, whereas the corresponding average scores for the Israeli normal population are 46.9 and 48.6 for PCS and MCS, respectively. ${ }^{5}$

Explanatory variables. Some variables, screened for their putative association with low HRQOL, were based on known associations between sociodemographic factors and quality of life. Other factors were measures of the severity of the coronary disease and symptoms of general ill health, such as sleep disturbances, known at the time of the operation and suspected of influencing quality of life even 1 year after the operation among survivors. The factors ascertained after discharge were participation in rehabilitation programs or readmission to the hospital during the first 3 months after the operation. The first was a possible determinant of quality of life because it indicated postdischarge motivation to get better and to continue community-based medical care. The sec- 


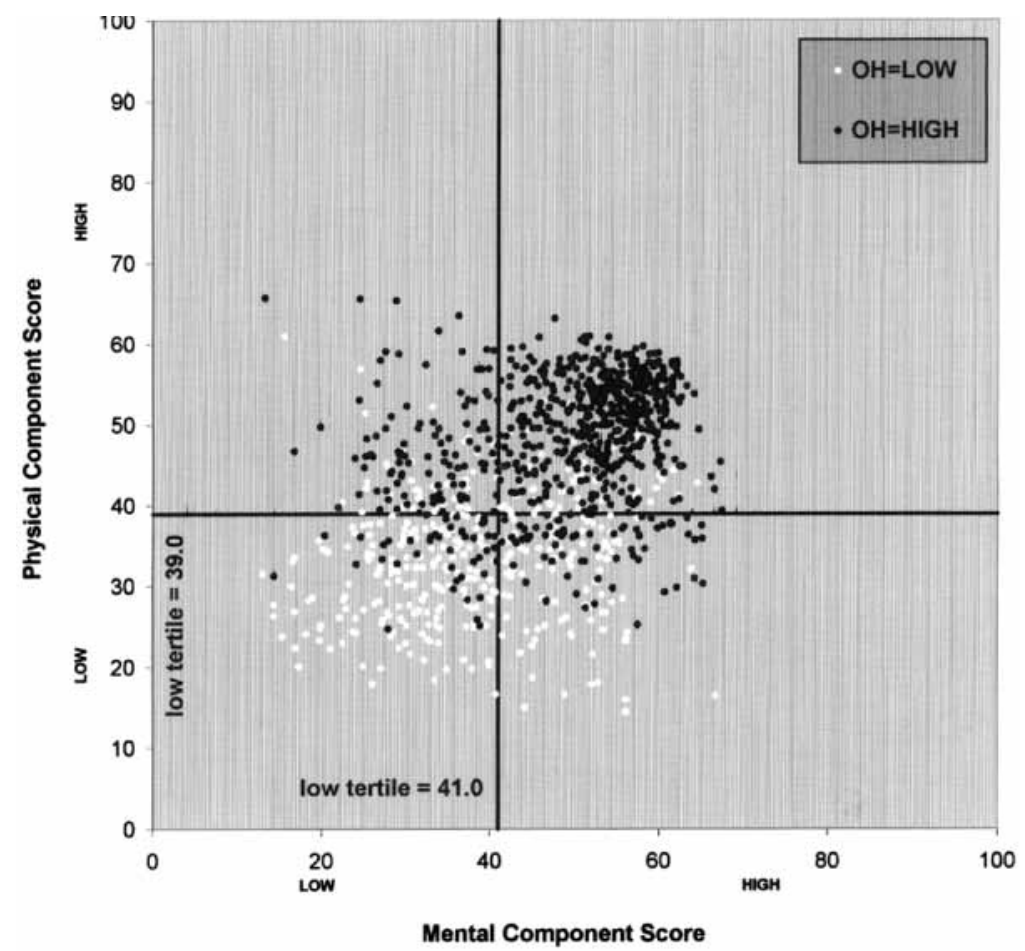

Fig 1. Association between the 3 study outcomes: SF-36 summary components (low PCS, low MCS) and a single question on overall health ( $\mathrm{OH}$; low overall health).

ond was an indicator of possible deterioration of health after the operation. The hospital where the operation was performed was ranked in relation to 30-day mortality after CABG as an indicator of quality of care that could affect quality of life among those who survived the operation. ${ }^{26}$

In Israel, factors depicting low sociodemographic status are associated with immigration, low education, and unemployment. The severity of illness at the time of the operation could have influenced the patient's perception of his or her state of health, even 1 year after the operation. Because the severity of the coronary disease involved screening 46 different factors, we decided to use a summary severity score. This summary was the individual's risk score derived from the final case-mix mortality models and developed for the entire CABG population. The score was the individual's sum of the $\beta$ coefficients corresponding to his or her risk profile according to the 7 factors included in the final case-mix model. ${ }^{26,27}$

Statistical analysis. The relationship among the scores of the 3 study outcomes was plotted in a scatter graph. The actual SF-36 scores at the cutoff points were used to describe the relationship of the dichotomized outcomes. The simultaneous presentation of the average scores on all 8 scales of the SF-36 in different patient subgroups are illustrated in spider diagrams.

Separate multivariate models were constructed for the determinants of low HRQOL in each of the 3 outcomes. Factors associated with low HRQOL at a $P$ value of .1 or less in a univariate analysis were introduced into the multiple logistic models for each of the respective outcomes.
The logistic models were as follows:

$$
\operatorname{logit}\left(\operatorname{Prob}\left[\mathrm{Y}_{\mathrm{i}} \mid \mathrm{X}_{\mathrm{i}}\right]\right)=\beta_{\mathrm{O}}+\sum_{\mathrm{j}} \beta_{\mathrm{j}} \mathrm{X}_{\mathrm{ij}}
$$

where $Y_{i}$ was the indicator for low HRQOL for each outcome for the individual (I), and $\mathrm{X}_{\mathrm{i}}=\left(\mathrm{X}_{\mathrm{i} 1}, \ldots, \mathrm{X}_{\mathrm{iM}}\right)$ was the patient's (M) characteristics. The estimated $\beta$ coefficient corresponded to the log odds of the risk factors with low HRQOL.

The 5\% subsample of patients with SF-36 questionnaire responses both before and after the operation was used to evaluate the effect of the preoperative HRQOL score on reporting low quality of life 1 year later. For each of the outcomes, the preoperative scores were added to the final models for the 3 outcomes of HRQOL 1 year after the operation.

The predictive power of each model in the study was assessed by using the $\mathrm{C}$ statistics, and the goodness of fit was evaluated with the Hosmer-Lemeshow test.

\section{Results}

The scatter graph of the patients' scores according to the 3 study outcomes is presented in Fig 1. The 2 summary components (PCS and MCS) of the SF-36 form 2 distinct clusters in the $\mathrm{CABG}$ population as designed, ${ }^{22}$ and the single question on overall health is correlated more with the physical than the mental component of the SF-36.

Patients with 1, 2, or 3 indicators of low social status were found to have a lower score on each of the 8 SF- 


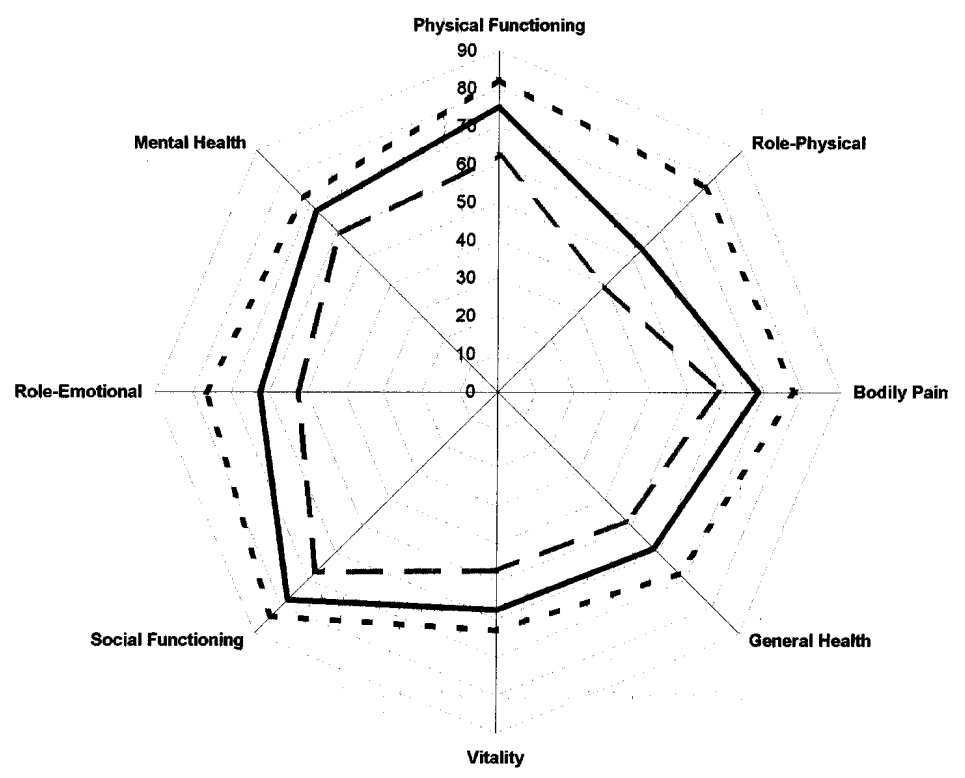

- - NONE

-ONE INDICATOR

- $2+$ INDICATORS

Fig 2. Quality of life 1 year after CABG. The 8 SF-36 scales are shown according to low sociodemographic status indicators: low education, immigrant status, and unemployment.

36 scales (Fig 2). The graph suggests a dose-effect phenomenon because more indicators of low social status are associated with lower quality of life. Women and men had an even more pronounced difference than social status, whereby women reported lower HRQOL in all 8 scales, with an especially low score in RolePhysical (Fig 3).

Results of the univariate analyses for factors associated with low HRQOL in each of the 3 study outcomes are presented in Table I. (Only factors associated at a $P$ value of less than .05 with at least one of the study outcomes are included.) Low HRQOL was more prevalent among female patients, immigrants, or those with limited education. Also, patients unemployed before the operation or those unengaged in physical activity (at work or during leisure time) tended to have a negative evaluation of their HRQOL. In reference to clinical characteristics, patients in the highest percentile of the severity of illness score, those hospitalized many times before the operation, or those who had chronic comorbid states, especially stroke, were more likely to report low quality of life 1 year after the operation. Similarly, patients who presented with symptom complaints before the operation (eg, angina pain) or who were given a diagnosis of hypertension had a higher probability of reporting low HRQOL. Of the postdischarge factors, surviving patients operated on in hospitals ranking high on 30-day mortality were more likely to report low quality of life, as were patients who did not participate in rehabilitation programs or those who needed readmission to the hospital in the first 100 days after the operation.

The multivariate analyses of each of the 3 study outcomes (Table II) confirmed, in general, the univariate analysis. They demonstrated that indicators of social disadvantage had a strong independent effect on low HRQOL in all 3 models, as did a high severity of illness score, sleep problems, and rehospitalization within 100 days of the operation. However, patients' preoperative hypertension, angina, and age younger than 61 years mainly influenced overall health and MCS but not physical health.

The model for overall health was more discriminative, as reflected by a higher $\mathrm{C}$ statistic $(0.76$ for overall health, 0.70 for PCS, and 0.70 for MSC) and the inclusion of 4 unique factors (Table II): a strong protective effect of both physical activity and participation in rehabilitation, an increased risk associated with patients operated on in hospitals ranking high on perioperative mortality, and female sex.

Of the 1724 patients who could be tracked, $73.6 \%$ responded with completed questionnaires. Patient characteristics (appendix) of responders and nonresponders were compared. Generally, differences between the groups were small. For example, in none of the operative or postoperative factors were the differences significant, 


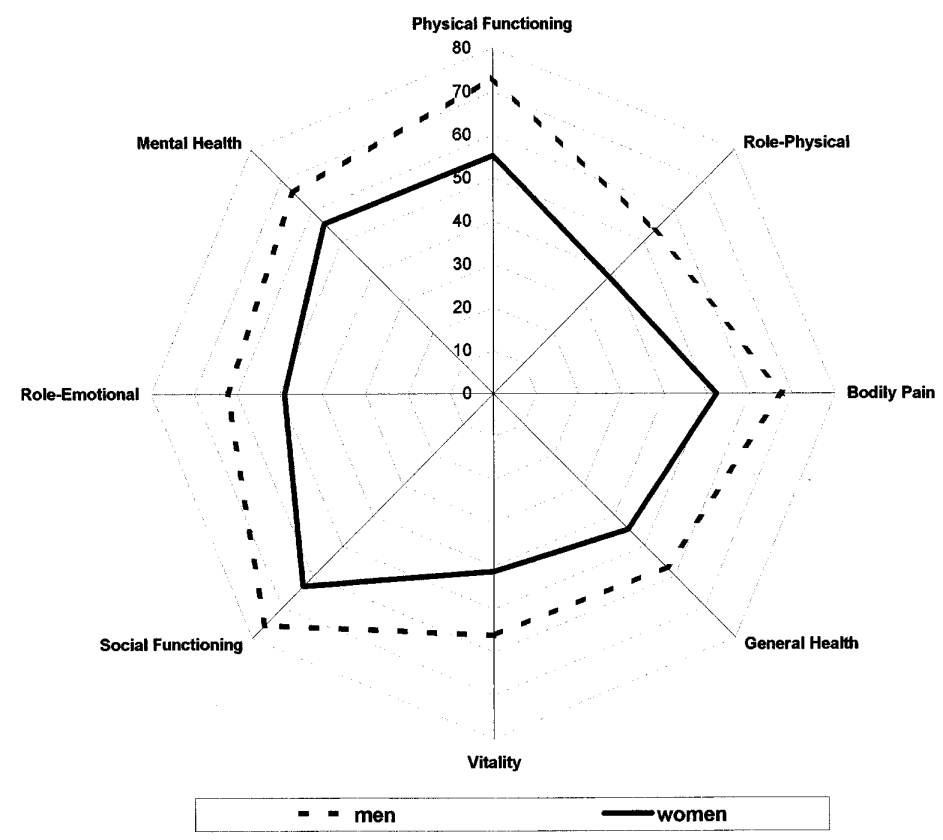

Fig 3. Quality of life 1 year after CABG. The 8 SF-36 scales are shown according to sex (average score).

indicating that responders were not sicker or in better clinical condition than nonresponders. Larger discrepancies were observed in some factors, whereby responders tended to have higher education (more academic professions), to be immigrants from Europe or America, to belong to an older age group, and to be less likely to have diabetes. Factors screened for operating room and postoperative complications are listed in the appendix.

The analysis of the 5\% random subgroup of 116 patients who responded to SF-36 questionnaires both before and after discharge showed that these patients were similar to the rest of the responders with respect to clinical and sociodemographic characteristics (data not shown). Preoperative SF-36 scores (actually the probability of scoring in the low tertile) were forced into HRQOL models as possible determinants of quality of life 1 year after the operation. The model-adjusted odds ratios for the preoperative scores in the respective postoperative HRQOL models were $1.2(P=.6)$ for overall health, $0.9(P=.8)$ for the PCS score, and 1.7 $(P=.3)$ for the MCS score.

\section{Discussion}

HRQOL is gaining momentum in the medical literature as an important outcome after medical and surgical interventions. However, what constitutes HRQOL is still under debate because different tools use different operational definitions. ${ }^{28}$ We chose the SF-36 health survey questionnaire, which uses subjective evaluations of HRQOL, rather than the opinion of caregivers. We also ended up with 3 study outcomes for each individual: the physical and mental health components of the SF-36 and an added single question on evaluation of health. The physical health component focused on a person's evaluation of his or her physical ability, such as the ability to perform activities of daily living and appreciation of how much his or her state of health limited or advanced his or her activities. The mental health component dealt with moods, vitality, and social functioning. We hoped that the subjective single overall evaluation by the patient would provide additional insight into his or her perceptions not covered by either of the SF-36 summary scores.

An important issue was how to model these 3 outcomes. In most of the published studies with the SF-36, the 2 summary components or the basic 8 scales are used as continuous outcomes summarized by the average. Others, like us, wished to identify patients who would be amenable to intervention to improve quality of life. ${ }^{29,30}$ It was therefore decided to focus on the group at the lowest end of the distribution of scores (ie, those with a relatively low HRQOL). This choice dichotomized the outcomes and could then be simply modeled by means of logistic regressions.

Another methodologic issue was whether symptoms of illness are part of the outcome of quality of 
Table I. Univariate analysis of putative determinants of low quality of life among 45- to 65-year-old survivors 1 year after CABG: Self-perception of low overall health, low physical health, and low mental health from the SF-36 questionnaire

\begin{tabular}{|c|c|c|c|c|}
\hline Risk variable & $\begin{array}{l}\text { No. of } \\
\text { patients }\end{array}$ & $\begin{array}{l}\text { Low overall } \\
\text { health } \dagger(\%)\end{array}$ & $\begin{array}{c}\text { Low physical } \\
\text { health } \dagger(\%)\end{array}$ & $\begin{array}{l}\text { Low mental } \\
\text { health } \dagger(\%)\end{array}$ \\
\hline \multicolumn{5}{|l|}{ Sociodemographic patient characteristics } \\
\hline \multicolumn{5}{|l|}{ Age $(y)$} \\
\hline $45-54$ & 309 & 28.7 & 26.2 & 31.7 \\
\hline $55-60$ & 406 & 36.8 & 33.5 & 35.7 \\
\hline $61-65$ & 555 & 35.6 & 31.2 & $26.3 \neq$ \\
\hline \multicolumn{5}{|l|}{ Sex } \\
\hline Male & 1081 & 31.6 & 27.2 & 28.2 \\
\hline Female & 189 & $49.7 \ddagger$ & $50.8 \ddagger$ & $44.4 \dagger$ \\
\hline \multicolumn{5}{|l|}{ Immigration status } \\
\hline Israeli born & 283 & 20.7 & 19.8 & 25.4 \\
\hline East European/American & 595 & 40.7 & 31.3 & 27.4 \\
\hline Middle EasternlNorth African & 379 & $35.3 \ddagger$ & $38.5 \ddagger$ & $40.1 \ddagger$ \\
\hline \multicolumn{5}{|l|}{ Education (y) } \\
\hline$>12$ & 488 & 28.9 & 22.6 & 20.9 \\
\hline $9-12$ & 402 & 31.2 & 30.5 & 31.6 \\
\hline$\leq 8$ & 284 & $47.5 \ddagger$ & $40.9 \ddagger$ & $41.6 \neq$ \\
\hline \multicolumn{5}{|l|}{ Profession } \\
\hline Academic & 538 & 28.9 & 23.8 & 20.5 \\
\hline White collar & 243 & 30.3 & 28.4 & 35.8 \\
\hline Blue collar & 377 & 42.0 & 39.5 & 41.1 \\
\hline Housewife & 62 & $46.6 \ddagger$ & $48.4 \ddagger$ & 41.9末 \\
\hline \multicolumn{5}{|l|}{ Employment before the operation } \\
\hline Full time & 666 & 22.4 & 24.1 & 26.3 \\
\hline Part time & 93 & 27.3 & 25.8 & 29.0 \\
\hline Early pension & 482 & 52.7 \$ & $39.8^{*}$ & $36.1^{*}$ \\
\hline \multicolumn{5}{|l|}{ Physical activity before the operation } \\
\hline No & 639 & 40.2 & 26.4 & 34.7 \\
\hline Yes & 629 & $28.3 \ddagger$ & $35.1 \ddagger$ & $26.6 \ddagger$ \\
\hline \multicolumn{5}{|l|}{ Clinical characteristics } \\
\hline \multicolumn{5}{|l|}{ Case-mix severity score§ } \\
\hline All else & 1061 & 32.5 & 28.2 & 28.8 \\
\hline $10 \%$ highest risk & 119 & $49.6 \ddagger$ & $53.5 \ddagger$ & $48.6 \div$ \\
\hline \multicolumn{5}{|c|}{ Hospitalization in past $2 \mathrm{y}$ before the operation } \\
\hline None & 401 & 23.0 & 20.0 & 26.2 \\
\hline $1-2$ & 703 & 37.0 & 32.7 & 30.6 \\
\hline$\geq 3$ & 157 & $51.7 \$$ & $49.7 \ddagger$ & $41.4+$ \\
\hline
\end{tabular}

life or could be considered among its determinants. We introduced into our models symptoms of illness at the time of the operation as putative determinants of HRQOL 1 year later. We agree with Wilson and Cleary ${ }^{8}$ that there should be a distinction between the presence of symptoms of illness and their functional effect. Function also depends on "characteristics like patient motivation, subjective perceptions, and expectations. Self-evaluation of quality-of-life represents a person's threshold and tolerance of symptoms and discomfort." 8
Our results ${ }^{4,31}$ also demonstrated that patients belonging to low social status groups were more likely to report low HRQOL; this was confirmed by others as well. Among patients undergoing postoperative bypass, this suggests that such patients may have difficulties in coping with the aftereffects of a major operation. Free-hand letters that patients often attached to their returned SF-36 questionnaires were full of complaints about the lack of "somebody to turn to" for advice after leaving the hospital. Better follow-up and support of such patients could improve 
Table I. Cont'd

\begin{tabular}{|c|c|c|c|c|}
\hline Risk variable & $\begin{array}{c}\text { No. of } \\
\text { patients }\end{array}$ & $\begin{array}{l}\text { Low overall } \\
\text { health } \dagger(\%)\end{array}$ & $\begin{array}{c}\text { Low physical } \\
\text { health } \dagger(\%)\end{array}$ & $\begin{array}{l}\text { Low mental } \\
\text { health } \dagger(\%)\end{array}$ \\
\hline \multicolumn{5}{|c|}{ Hypertension before the operation } \\
\hline No & 587 & 28.1 & 26.1 & 25.6 \\
\hline Yes & 683 & $39.6 \neq$ & $34.7 \ddagger$ & $35.0 \%$ \\
\hline \multicolumn{5}{|l|}{ Arrhythmia before the operation } \\
\hline No & 1123 & 33.6 & 30.0 & 29.6 \\
\hline Yes & 146 & 38.9 & 36.3 & $39.0 *$ \\
\hline \multicolumn{5}{|c|}{ Chronic obstructive lung disease before the operation } \\
\hline No & 1209 & 33.6 & 30.2 & 29.9 \\
\hline Yes & 61 & $45.9^{*}$ & $44.3 *$ & $45.9 \ddagger$ \\
\hline \multicolumn{5}{|c|}{ Peripheral vascular disease before the operation } \\
\hline No & 1159 & 32.6 & 29.3 & 29.9 \\
\hline Yes & 91 & $52.3 \ddagger$ & $47.3 \div$ & $41.8^{*}$ \\
\hline \multicolumn{5}{|c|}{ Cerebrovascular event before the operation } \\
\hline None & 1206 & 32.8 & 29.9 & 29.9 \\
\hline Transient ischemic attack & 21 & 55.0 & 42.7 & 47.6 \\
\hline Cerebrovascular accident & 43 & $66.7 \ddagger$ & $46.5^{*}$ & $44.2 *$ \\
\hline \multicolumn{5}{|c|}{ Carotid stenosis before the operation } \\
\hline No & 1208 & 33.3 & 30.1 & 30.3 \\
\hline Yes & 59 & $53.9 \dagger$ & $44.1 *$ & 37.3 \\
\hline \multicolumn{5}{|c|}{ Angina pectoris before the operation } \\
\hline No & 235 & 19.9 & 22.6 & 23.0 \\
\hline Yes & 1033 & $37.5 \ddagger$ & $32.6+$ & $32.4 \ddagger$ \\
\hline \multicolumn{5}{|c|}{ Sleep disturbance before the operation } \\
\hline No & 1112 & 31.8 & 29.1 & 28.2 \\
\hline Yes & 156 & $51.7 \ddagger$ & $42.3 \ddagger$ & $48.7 \ddagger$ \\
\hline \multicolumn{5}{|l|}{ Other characteristics } \\
\hline \multicolumn{5}{|c|}{ Hospital 30-day risk-adjusted mortality } \\
\hline Low $(1.2 \%-2.3 \%)$ & 480 & 29.5 & 29.2 & 30.2 \\
\hline Medium $(2.5 \%-4.8 \%)$ & 602 & 34.2 & 29.7 & 29.1 \\
\hline High $(6.8 \%-6.9 \%)$ & 186 & $46.8 \div$ & $38.2^{*}$ & 37.1 \\
\hline \multicolumn{5}{|c|}{ Rehabilitation within 3 mo after CABG } \\
\hline No & 1143 & 36.1 & 31.8 & 31.2 \\
\hline Yes & 127 & $17.5 \ddagger$ & $21.3^{*}$ & 25.2 \\
\hline \multicolumn{5}{|c|}{ Rehospitalization within 3 mo after CABG } \\
\hline No & 1042 & 30.7 & 28.0 & 29.1 \\
\hline Yes & 228 & $50.5 \neq$ & $43.0 \ddagger$ & $37.7^{*}$ \\
\hline
\end{tabular}

Missing values do not appear.

$* .01<P \leq .05$ ( $\chi^{2}$ test $)$.

$\dagger$ Lowest third of the percentile distribution.

$\ddagger P \leq .01$ ( $\chi^{2}$ test).

$\S$ Variables that entered the case-mix final model: age greater than 70 years, left ventricle dysfunction, creatinine level of greater than 1.4 mg/dL, emergency-urgent operation, involvement of 3 or more vessels, and diabetes mellitus.

their situation. For example, there should be a policy of encouraging participation in rehabilitation programs. In Israel few patients $(5 \%)$ use existing rehabilitation facilities because of a lack of encouragement by surgeons and limited financial coverage by the sick funds. However, according to patients' letters, other community services fail to provide the postdischarge aid needed. Rehabilitation programs could also help patients lacking self-motivation for physical activity to begin such activities and thus improve their quality of life after CABG. Our study demonstrated that both physical activity and participation in rehabilitation were strong protective factors against evaluating low overall health. Special attention should be given to women undergoing CABG. Although only $20 \%$ of patients undergoing CABG are women, they tended to have higher early mortality rates ${ }^{27}$ and for those who survived, half evaluated their HRQOL as low a year after CABG. Very few of these women $(n=49)$ aged 45 to 65 years were gainfully employed before the operation. However, although employed men were protected against 
Table II. Multivariate analysis of low HRQOL (logistic regression model)

\begin{tabular}{|c|c|c|c|}
\hline Risk factor & $\begin{array}{c}\text { Low overall health, } \\
\text { model } 1 \\
\text { adjusted OR }\end{array}$ & $\begin{array}{c}\text { Low physical health } \\
\text { (PCS), model } 2 \\
\text { adjusted OR }\end{array}$ & $\begin{array}{c}\text { Low mental health } \\
\text { (MCS), model } 3 \\
\text { adjusted OR }\end{array}$ \\
\hline \multicolumn{4}{|l|}{ Sociodemographic and behavioral factors } \\
\hline \multicolumn{4}{|l|}{ Age $(y)$} \\
\hline $45-54$ & 1.00 & 1.00 & 1.00 \\
\hline $55-60$ & 1.29 & 1.2 & 1.03 \\
\hline $61-65$ & $0.63 *$ & 0.8 & $0.52 \dagger$ \\
\hline \multicolumn{4}{|l|}{ Sex } \\
\hline $\mathrm{M}$ & 1.00 & 1.00 & 1.00 \\
\hline $\mathrm{F}$ & $2.03 *$ & 1.45 & 1.23 \\
\hline \multicolumn{4}{|l|}{ Immigration status } \\
\hline Israeli born & 1.00 & 1.00 & 1.00 \\
\hline Eastern European/American & $2.67 \dagger$ & $1.88 \dagger$ & 1.2 \\
\hline Middle Eastern/North African & $1.79 \dagger$ & $2.46 \dagger$ & $1.94 \dagger$ \\
\hline \multicolumn{4}{|l|}{ Education (y) } \\
\hline$>12$ & 1.00 & 1.00 & 1.00 \\
\hline $9-12$ & 0.98 & $1.39 *$ & $1.53^{*}$ \\
\hline$\leq 8$ & $2.10 \dagger$ & $1.70^{*}$ & $1.83 \dagger$ \\
\hline \multicolumn{4}{|l|}{ Employment } \\
\hline Full or part time & 1.00 & 1.00 & 1.00 \\
\hline Early pension & $3.10 \dagger$ & $1.58 *$ & $1.35^{*}$ \\
\hline \multicolumn{4}{|l|}{ Physical activity } \\
\hline No & 1.00 & 1.00 & 1.00 \\
\hline Yes & $0.66^{*}$ & 0.9 & 0.81 \\
\hline \multicolumn{4}{|l|}{ Clinical factors } \\
\hline Case-mix severity score & $1.24 *$ & $1.63 \dagger$ & $1.49 \dagger$ \\
\hline \multicolumn{4}{|l|}{ Angina pain symptoms } \\
\hline No & 1.00 & 1.00 & 1.00 \\
\hline Yes & $2.10 \dagger$ & 1.32 & $1.44 *$ \\
\hline \multicolumn{4}{|l|}{ Sleep problems } \\
\hline No & 1.00 & 1.00 & 1.00 \\
\hline Yes & $1.80 \dagger$ & $1.46^{*}$ & $2.30 \dagger$ \\
\hline \multicolumn{4}{|l|}{ Hypertension } \\
\hline No & 1.00 & 1.00 & 1.00 \\
\hline Yes & $1.35^{*}$ & 1.2 & $1.36^{*}$ \\
\hline \multicolumn{4}{|c|}{ Hospital 30-day risk-adjusted mortality } \\
\hline Low $(1.2 \%-2.3 \%)$ & 1.00 & 1.00 & 1.00 \\
\hline Medium $(2.5 \%-4.8 \%)$ & 1.00 & 1.00 & 1.00 \\
\hline High $(6.8 \%-6.9 \%)$ & $1.70 \dagger$ & 1.19 & 1.2 \\
\hline \multicolumn{4}{|l|}{ Rehospitalization after discharge } \\
\hline No & 1.00 & 1.00 & 1.00 \\
\hline Yes & $2.10 \dagger$ & $1.75 \dagger$ & $1.42 *$ \\
\hline \multicolumn{4}{|l|}{ Rehabilitation after discharge } \\
\hline No & 1.00 & 1.00 & 1.00 \\
\hline Yes & $0.46 \dagger$ & 0.71 & 0.87 \\
\hline C statistics & 0.765 & 0.702 & 0.706 \\
\hline
\end{tabular}

$O R$, Odds ratio.

$* .001<P \leq .05$.

$\dagger P \leq .001$.

‡Case-mix severity score was entered as a continuous variable.

reporting low quality of life, this was less true for women. For both groups, those labeled "housewife" and those labeled "gainfully employed," there was a high proportion of patients who reported negatively on overall health.
A comparison of the models constructed for each of the 3 outcomes demonstrated that although all 3 models had similar determinants, the single question on overall health yielded a more discriminating model. It included 4 unique additional factors: no physical activ- 
ity, nonparticipation in rehabilitation, female sex, and having been operated on in a hospital with high 30-day mortality rates. The differences between the model for overall health and the other 2 outcomes could mean that a general subjective evaluation by the patient of his or her state of health involved a wider view of health and life unparalleled by the more specific questions that formed the other 2 outcomes. Furthermore, we believe that a simple general question on overall health could replace a long questionnaire on HRQOL ${ }^{32}$ if the purpose was to identify patients reporting low quality of life. In any event, there is an advantage in including a general question on health, beyond the specific scales, in all HRQOL evaluations.

We restricted the present analysis to middle-aged patients because, contrary to intuition, older patients after CABG fared better in their self-evaluation of HRQOL than those in middle age. ${ }^{21}$ In this study, although older patients were excluded, patients over 60 seemed to be protected against reporting low HRQOL relative to their younger counterparts. This could be because younger patients (ie, below 60 years of age) faced different challenges in their postoperative lives than older patients, especially the expectation that they return to work. We concluded that each age group deserved a separate analysis.

A special effort was made to sample patients in the preoperative period and ask them to fill out SF-36 questionnaires. This was done to examine the possibility that some patients tended to report either high or low quality of life, regardless of the operation. If such tracking in reporting HRQOL occurred, we expected the preoperative SF-36 score to play an important role in the postoperative HRQOL models. This was not what we found. SF-36 results before the operation, when forced into the logistic model for HRQOL 1 year after the operation, did not add significant information. This finding is in contrast with other studies ${ }^{13}$ reporting that a patient's evaluation of his or her state of health before the operation was an important predictor of the evaluation after the operation. Our explanation for this difference is that information on sociodemographic factors, physical activity, and ischemic heart disease symptoms, which in our study were provided by the preoperative interview, competed unfavorably within the models with the preoperative SF-36 scores. In studies in which no preoperative interviews took place, the SF-36 provided the only insight into the patient's situation before the operation and therefore provided significant information.

The main drawback of the study was the low response rate. The fact that over $10 \%$ of the patients were either foreign residents or relocated after the operation resulted in a failure to contact $17 \%$ of the patients after 1 year. Among those contacted, $73.6 \%$ filled out the questionnaires. It should be remembered that this is a nation-wide study in which contact with patients is less intense than if it were conducted in a smaller region. Failure to respond for those who received the questionnaires could have been related to the length of the SF-36 or to the time window of 1 year. This period could have been too long for many patients who returned to normal lives and rejected being reminded of the operation.

Nonresponders were not sicker than responders. No differences were found in their operative and postoperative factors. However, some differences were found in sociodemographic factors; patients who were educated, older, and new immigrants tended to respond more, as did patients who participated in rehabilitation.

\section{Conclusion}

At least a third of the Israeli CABG population did not evaluate their HRQOL as good 1 year after the operation. If such patients were either women or of low sociodemographic status or aware of a severe coronary disease at the time of the operation, their evaluation of postoperative health was even worse. Because all factors identifying this weak group among the CABG population were known at the time of the operation, they could be identified and dealt with at that time. Thus targeting such patients as a priority for encouragement to participate in rehabilitation programs and follow-up after hospital discharge could improve quality of life among patients undergoing CABG. Selecting such patients for community support could be the first step in improving quality of life for those most in need, even if similar support for all patients is impractical because of a lack of resources.

The Israeli Coronary Artery Bypass Graft study (ISCAB) consortium (from all Cardiac Surgery Departments in Israel and the Israeli Ministry of Health): Appelbaum Azay, MD; Amit Nima, RN; Bar-El Yaron, MD; Berlovitz Yitzhak, MD; Biteran Dani, MD; Cohen Amram, MD; Kaplinsky Elieser, MD; Lavee Jacob, MD; Merin Gideon, MD; Milo Simcha, MD; Mozes Benjamin, MD; Oretzki Gideon, MD; Sahar Gideon, MD; Schachner Arie, MD; Smolenski Aram, MD; Vidne Bernardo, MD; Yakirevitch Vladimir MD.

Received for publication June 21, 2000; accepted for publication Sept 22, 2000.

Address for reprints: Elisheva Simchen, MD, MPH, School of Public Health, Hadassah Medical Center, Ein Kerem, Jerusalem 91120, Israel (E-mail: sara.sachs@moh.health.gov.il or esimchen@vms.huji.ac.il). 


\section{REFERENCES}

1. Edward FH, Clark RE, Schwartz M. Coronary artery bypass grafting the society of thoracic surgeon's national database experience. Ann Thorac Surg 1994;57:2-19.

2. Clark RE. The society of thoracic surgeons national database status report. Ann Thorac Surg 1994;57:20-6.

3. Duits AA, Boeker S, Taams MA, Passchier J, Erdman RAM. Prediction of quality-of-life after coronary artery bypass graft surgery: a review and evolution of multiple, recent studies. Psychosomatic Med 1997;59:257-68.

4. Ashing-Giwa K, Ganz PA, Petersen L. Quality-of-life of AfricanAmerican and white long term breast carcinoma survivors. Cancer 1999;85:418-26.

5. Epstein LN, Sagiv-Schifter T, Shabtai E. Validation of the SF-36item short form health survey (Hebrew version) in the adult population of Israel. Med Care 1998;36:1361-70.

6. Pearlman RA, Jonsen A. The use of quality-of-life consideration in medical decision-making. Ann Intern Med 1985;97:420-5.

7. Leplege A, Hunt $S$. The problem of quality-of-life in medicine. JAMA 1997;278:47-50.

8. Wilson IB, Cleary PD. Linking clinical variables with health related quality-of-life: a conceptual model of patient outcomes. JAMA 1995;273:59-65.

9. Mayou R, Bryant B. Quality-of-life after coronary artery surgery. Q J Med 1987;62:239-48.

10. Folks DG, Blake DJ, Fleece L, Sokol RS, Freeman AM. Qualityof-life six months after CABG; a preliminary report. South Med J 1986;79:397-9.

11. Papadantonaki A, Stotts NA, Paul SM. Comparison of quality-oflife before and after coronary artery bypass surgery and percutaneous transluminal angioplasty. Heart Lung 1994;23:45-52.

12. Booth DC, Deupree RH, Hultgren HN, DeMaria AN, Scott SM, Luchi RJ. Quality of life after bypass surgery for unstable angina: 5-year follow-up results of a Veterans Affairs Cooperative Study. Circulation 1991;83:87-95.

13. Caine N, Harrison SCW, Sharples LD, Wallwork J. Prospective study of quality-of-life before and after coronary artery bypass grafting. BMJ 1991;302:511-6.

14. Chocron S, Etievent JP, Viel JF, Dussaucy A, Clement F, Alwan $\mathrm{K}$, et al. Prospective study of quality of life before and after open heart operation. Ann Thorac Surg 1996;61:153-7.

15. Weintraub WS, Mauldin PD, Becker E, Kosinski AS, King SB. A comparison of the costs of and quality-of-life after coronary angioplasty or coronary surgery for multivessel coronary after disease: results from the Emory Angioplasty versus Surgery Trial (EAST). Circulation 1995;92:2831-40.

16. Pocock SJ, Henderson RA, Seed P, Treasure T, Hampton JR. Quality-of-life, employment status and anginal symptoms after coronary angioplasty or bypass surgery: 3-year follow-up in the Randomized Intervention Treatment of Angina (RITA) trial. Circulation 1996;94:135-42.

17. Cleary PD, Epstein AM, Oster G, Morrissey GS, Stason WB, Debussey S, et al. Health-related quality of life among patients undergoing percutaneous transluminal coronary angioplasty. Med Care 1991;29:939-50.
18. Hlatky MA, Charles ED, Nobrego F, Gelman K, Johnstone I, Melvin J, et al. Initial functional and economic status of patients with multivessel Coronary artery disease randomized in the Bypass Angioplasty Revascularisation Investigation (BARI). Am J Cardiol 1995;75:34C-41C.

19. Raft D, McKee DC, Popio KA, Haggerty JJ. Life adaptation after percutaneous transluminal coronary angioplasty and coronary artery bypass grafting. Am J Cardiol 1985;56:395-8.

20. Sjorland H, Caidahl K, Wiklund I, Haglid M, Hartford M, Karlson BW, et al. Impact of coronary artery bypass grafting on various aspects of quality of life. Eur J Cardiothorac Surg 1997;12:612-9.

21. Guardagnoli E, Ayanian JZ, Cleary PD, Comparison of patientreported outcomes after elective coronary artery bypass grafting in patients aged $<65$ and $>65$ years. Am J Cardiol 1992;70:60-4.

22. McHorney CA, Ware JE, Raczek AE. The MOS-36 item shortform health survey (SF-36). II. Psychometric and clinical tests of validity in measuring physical and mental health constructs. Med Care 1993;31:247-63.

23. McHorney CA, Ware JE, Rogers W, Raczek AE, Lu JF. The validity and relative precision of MOS short and long form health status scales and Dartmouth COOP charts: results from the medical outcomes study. Med Care 1992;30(Suppl):MS253-65.

24. Garratt AM, Ruta DA, Abdalla MI, Buckingham JK, Russell IT. The SF-36 health survey questionnaire: an outcome measures suitable for routine use within the NHS? BMJ 1993;306:1440-4.

25. Ware JE, Kosinski M, Keller DS. SF-36 physical and mental health summary scales: a user's manual. Boston: The Health Institute, New England Medical Center; 1994. p. 3.2-5.5.

26. Mozes B, Liraz O, Galai N, Simchen E, for the ISCAB consortium. A national study of postoperative mortality associated with coronary artery bypass grafting in Israel. Ann Thorac Surg 1998;66:1254-63.

27. Simchen E, Galai N, Zitser GY, Braun D, Mozes B, for the ISCAB consortium. Sequential logistic models for 30 days mortality after CABG: pre-, intra- and post-operative experience: the ISCAB study. Eur J Clin Epidemiol 2000;16:543-55.

28. Anderson RT, Aaronson NK, Bullinger M, Mcbee WL. A review of the progress towards developing health related quality-of-life instruments for international clinical studies and outcomes research. Pharmacoeconomics 1996;4:336-55.

29. Lim LL, Johnson NA, O'Conell RL, Heller RF. Quality-of-life and later adverse health outcomes in patients with suspected heart attack. Aust N Z J Public Health 1998;22:540-6.

30. Merkus MP, Jager KJ, Dekker FW, de Haan RJ, Boeschoten EW, Krediet RT. Predictors of poor outcome in chronic dialysis patients: The Netherlands Cooperative Study on the Adequacy of Dialysis. Am J Kidney Dis 2000;35:69-79.

31. Hemingway H, Nicholson A, Roberts R, Marmot M. The impact of socioeconomic status on health functioning as assessed by the FS-36 questionnaire: the Whitehall II study. Am J Public Health 1997;87:1484-90.

32. Sloan JA, Loprinzi CL, Kuross SA, Miser AW, O'Fallon JR, Mahoney MR, et al. Randomized comparison of four tools measuring overall quality of life in patients. J Clin Oncol 1998;16:3662-73 
Appendix. Comparison of responders and nonresponders to quality-of-life questionnaires among 45- to 65-yearold survivors 1 year after $C A B G$

\begin{tabular}{|c|c|c|c|c|c|c|}
\hline \multirow[b]{3}{*}{ Risk variable ${ }^{* \dagger}$} & \multirow{2}{*}{\multicolumn{2}{|c|}{ Responders $(n=1270)$}} & \multicolumn{4}{|c|}{ Nonresponders $(n=815)$} \\
\hline & & & \multicolumn{2}{|c|}{ Refused $(n=454)$} & \multicolumn{2}{|c|}{ Lost to follow-up $(n=361)$} \\
\hline & $n$ & $\%$ & $n$ & $\%$ & $n$ & $\%$ \\
\hline \multicolumn{7}{|l|}{ Age (y) } \\
\hline $45-54$ & 356 & 28.0 & 182 & 34.0 & 107 & 29.6 \\
\hline $55-60$ & 359 & 28.3 & 147 & 36.0 & 112 & 31.0 \\
\hline $61-65$ & 555 & 43.7 & 125 & 29.0 & 142 & 39.0 \\
\hline \multicolumn{7}{|l|}{ Immigration status } \\
\hline Israel & 283 & 22.5 & 129 & 29.5 & 106 & 29.3 \\
\hline Europe/America & 595 & 47.3 & 163 & 36.0 & 147 & 41.6 \\
\hline Asia/Africa & 379 & 30.2 & 154 & 34.0 & 105 & 29.6 \\
\hline \multicolumn{7}{|l|}{ Living status } \\
\hline Alone & 51 & 4.0 & 20 & 5.0 & 33 & 9.0 \\
\hline Not alone & 1214 & 96.0 & 433 & 95.0 & 324 & 91.0 \\
\hline \multicolumn{7}{|l|}{ Education (y) } \\
\hline$\leq 8$ & 284 & 24.2 & 110 & 27.3 & 97 & 31.1 \\
\hline $9-12$ & 488 & 41.6 & 193 & 48.4 & 123 & 39.4 \\
\hline$>12$ & 402 & 34.2 & 103 & 24.3 & 92 & 29.5 \\
\hline \multicolumn{7}{|l|}{ Profession } \\
\hline Academic & 538 & 44.1 & 153 & 35.4 & 134 & 39.3 \\
\hline White collar & 243 & 19.9 & 107 & 24.7 & 74 & 21.7 \\
\hline Blue collar & 377 & 30.9 & 150 & 34.7 & 110 & 32.2 \\
\hline Housewife & 62 & 5.1 & 22 & 5.1 & 23 & 6.7 \\
\hline \multicolumn{7}{|c|}{ Employment before the operation } \\
\hline Full time & 666 & 53.4 & 247 & 56.3 & 184 & 53.0 \\
\hline Part time & 93 & 7.5 & 28 & 6.4 & 28 & 8.1 \\
\hline Early pension & 487 & 39.1 & 164 & 37.3 & 135 & 38.9 \\
\hline \multicolumn{7}{|c|}{ Smoking status before the operation } \\
\hline Nonsmoker & 398 & 31.3 & 129 & 28.4 & 117 & 32.4 \\
\hline Past smoker & 484 & 38.1 & 163 & 35.9 & 121 & 33.5 \\
\hline Current smoker & 388 & 30.6 & 162 & 35.7 & 123 & 34.1 \\
\hline \multicolumn{7}{|c|}{ Diabetes mellitus before the operation } \\
\hline No & 919 & 72.4 & 298 & 65.6 & 247 & 68.4 \\
\hline Yes & 351 & 27.6 & 156 & 34.4 & 114 & 31.6 \\
\hline \multicolumn{7}{|c|}{$\begin{array}{l}\text { Canadian heart association criteria } \\
\text { before the operation }\end{array}$} \\
\hline No angina & 225 & 18.4 & 83 & 19.1 & 57 & 16.2 \\
\hline I, II & 338 & 27.6 & 102 & 23.5 & 79 & 22.4 \\
\hline III, IV & 434 & 35.4 & 172 & 39.6 & 175 & 49.7 \\
\hline $\mathrm{V}$ & 228 & 18.6 & 77 & 17.7 & 41 & 11.7 \\
\hline \multicolumn{7}{|c|}{ Rehabilitation after CABG } \\
\hline No & 1143 & 90.0 & 441 & 97.1 & 357 & 98.9 \\
\hline Yes & 127 & 10.0 & 13 & 2.9 & 4 & 1.1 \\
\hline
\end{tabular}

*Only characteristics with differences at a $P$ value of less than .05 are presented. Preoperative variables screened were as follows: sex, physical activity, hypertension, peripheral vascular disease, and stroke. Operative variables screened were as follows: complicated operation and incomplete revascularization. Postoperative variables screened were as follows: additional operation during the admission, temperature greater than $38.5^{\circ} \mathrm{C}$, wound infection, pneumonia, prolonged mechanical ventilation, blood transfusions of greater than 5 portions, and long hospital stay. The only postdischarge variable screened was readmission to the hospital within 3 months.

$†$ Missing values do not appear. 